\title{
Early lactation production, health, and welfare characteristics of cows selected for extended lactation
}

\author{
J. O. Lehmann, ${ }^{1}$ L. Mogensen, and T. Kristensen \\ Department of Agroecology, Aarhus University-Foulum, Blichers Allé 20, DK-8830 Tjele, Denmark
}

\begin{abstract}
Some cows are able to achieve relatively high milk yields during extended lactations beyond $305 \mathrm{~d}$ in milk, and farmers may be able to use this potential by selecting the most suitable cows for an extended lactation. However, the decision to postpone insemination has to rely on information available in early lactation. The main objectives of this study were, therefore, to assess the association between the information available in early lactation and the relative milk production of cows on extended lactation, and to investigate if this information can be used to differentiate time of first insemination between cows. Data came from 4 Danish private herds practicing extended lactation in which some cows are selected to have a delayed time of planned first insemination. Average herd size varied from 93 to 157 cows, and milk yield varied from 7,842 to $12,315 \mathrm{~kg}$ of energy-corrected milk (ECM) per cow per year across herds. The analysis was based on 422 completed extended lactations $(427 \pm 87 \mathrm{~d})$, and each lactation was assigned to 1 of 3 (low, medium, and high) milk performance groups (MPG) within parity group within herd based on a standardized lactation yield. For cows in the high MPG, peak ECM yield, and ECM yield at dry off were significantly greater, the relative reduction in milk yield between 60 and $305 \mathrm{~d}$ in milk was significantly smaller, and a smaller proportion had a body condition score (scale: $1-5)$ at dry off of 3.5 or greater compared with cows in low MPG. Previous lactation days in milk at peak ECM yield and ECM yield at dry off were higher, the relative reduction in milk yield between 60 and $305 \mathrm{~d}$ in milk was smaller, and the number of inseminations per conception was higher for multiparous cows in high MPG compared with low. Current lactation ECM yield at second and third milk recording were greater for cows in high MPG compared with low. A principal component analysis indicated that variables related to fertility, diseases,
\end{abstract}

Received March 11, 2016.

Accepted November 2, 2016.

${ }^{1}$ Corresponding author: JesperO.Lehmann@agro.au.dk and milk yield explained most of the total variation between primiparous cows, whereas variables related to milk yield, fertility, and days in milk at peak yield were the most dominating for multiparous cows. Our study indicated that milk yields in previous lactation and at second and third milk recording correlate well with milk production potential, and therefore, may be promising indicators when selecting the most suitable cows for extended lactation.

Key words: extended lactation, dairy cow, milk production, indicator

\section{INTRODUCTION}

Dairy farmers make management decisions on a daily basis related to different areas including culling, feeding, disease treatments, and reproduction. Available software solutions aimed at supporting the farmer with these decisions range from simple spreadsheet models to more complex and advanced systems. A common trait for these software solutions is that they rely on potentially a large amount of data including cow-specific characteristics that are processed to support the farmer in evaluating the expected outcome of a decision. Typically, decisions are evaluated in relation to their effect on cow economic performance.

One important driver for the expected economic performance of a cow is the milk production level and profile during lactation, which are directly affected by feeding and indirectly by a range of factors. These factors include general management practices (AlbarránPortillo and Pollott, 2011), breed and parity (Nielsen et al., 2003), age at first calving in relation to first parity performance (Ettema and Santos, 2004), and previous days dry (Funk et al., 1987; Steeneveld et al., 2013). Also, reproduction, lameness (Green et al., 2002, Onyiro et al., 2008), calving difficulty (Thompson et al., 1983; Barrier and Haskell, 2011), some diseases in early lactation (Fourichon et al., 1999; Rajala-Schultz et al., 1999), and BCS at calving (Roche et al., 2009) are known to affect milk production. Furthermore, BCS at calving may interact with reproduction, health, and welfare of the cow (Roche et al., 2009). 
In industrialized dairy farming systems, much information concerning these factors is available from compulsory and voluntary herd and cow recording schemes, which, in combination with personal experience, may be used in everyday decision-making. These decisions could involve differentiating time of first insemination after calving between individual cows and thereby select all or some cows to have insemination delayed. In turn, this would manage these cows for an extended lactation beyond 305 DIM.

Intuitively, managing cows for extended lactations increases herd average DIM, and this could reduce average milk production if cows follow the general curvature of a standard lactation curve. However, studies indicate that cows completing an extended lactation can produce equal amounts of milk per feeding day (lactating plus dry days) as cows completing a lactation of traditional length (Arbel et al., 2001; Österman and Bertilsson, 2003; Lehmann et al., 2016). Furthermore, these studies indicated the presence of a large variation between cows in individual milk production per feeding day, and it is, therefore, possible that some of the cows with the lowest milk production potential should have been inseminated earlier.

Milk production per feeding day extends to milk production per annual cow, which again extends to herd milk production. The difference between the individual cow and herd average milk production per feeding day, therefore, reflects the contribution of the individual cow toward herd milk production. We hypothesize that differentiating time of first insemination between cows can be a part of an optimization strategy where the milk production potential is used during an extended lactation. However, farmers have to do this differentiation in early lactation based on the available information on individual cow characteristics, which could include factors such as previous milk yield, disease, and reproduction that may affect milk production performance for the remaining part of the lactation.

The main objectives of this study were, therefore, to assess the association between the information available in early lactation and relative milk production of cows on extended lactation, and to investigate if this information can be used to differentiate time of first insemination between cows.

\section{MATERIALS AND METHODS}

\section{Herds}

Four farmers actively managing selected cows for extended lactation participated in the project from January 2013 to December 2015. Each farmer had their own definition of the length of both a planned short and a planned long lactation, and they managed this by altering time of first insemination relative to calving. The 4 farms differed in size, breed, replacement rate, and milk production level (Table 1), and across herds, the average calving interval ranged from 425 to $541 \mathrm{~d}$ for primiparous and from 423 to $519 \mathrm{~d}$ for multiparous cows. Mean parity of multiparous cows was 2.7 (SD = 1.1 ) with $59 \%$ in second parity, $25 \%$ in third parity, and $16 \%$ in greater parities. All 4 herds were managed in a confinement system and fed a TMR.

Table 1. Annual herd characteristics

\begin{tabular}{lcccc}
\hline & \multicolumn{3}{c}{ Herd } \\
\cline { 2 - 5 } Item & 1 & 2 & 3 & 4 \\
\hline Annual cows $^{1}$ & 157 & 93 & 154 & 132 \\
Breed & Holstein & Holstein & Crosses $^{2}$ & Jersey \\
System & Conventional & Organic & Organic & Organic \\
Milking system & Parlor & Robot & Parlor & Robot \\
Barn type & Cubicles & Cubicles & Deep litter & Deep litter \\
Milk per annual cow, kg & 12,358 & 10,479 & 7,083 & 6,151 \\
Mean fat, \% & 4.05 & 3.83 & 4.74 & 5.82 \\
Mean protein, \% & 3.29 & 3.34 & 3.62 & 4.11 \\
Milk per annual cow, kg of ECM & 12,315 & 10,209 & 7,842 & 7,849 \\
Replacement rate, \% & 52.0 & 32.4 & 38.8 & 29.4 \\
Age at first calving, mo. (SD) & $24.9(2)$ & $25.3(2.4)$ & $25.8(1.2)$ & $26.9(3.3)$ \\
Calving interval primiparous, d (SD) & $425(59)$ & $511(77)$ & $474(45)$ & $541(111)$ \\
Calving interval multiparous, d (SD) & $422(51)$ & $503(108)$ & $483(45)$ & $519(115)$ \\
Planned short lactation length, mo. (d) & $13(395)$ & $14(426)$ & $15(456)$ & $13(395)$ \\
Planned long lactation length, mo. (d) & $16(487)$ & $17(517)$ & $18(548)$ & $16(487)$ \\
\hline${ }^{1}$ One annual cow is an average cow fed for 365 d. & & & & \\
${ }^{2}$ Crosses of Holstein, Red Danish, and Jersey. & & & & \\
${ }^{3}$ Organic certification according to Danish standards. & & &
\end{tabular}


Table 2. Distribution of primi- and multiparous cows in relation to planned lactation length and completion rates of cows on a long lactation by the end of year 2015

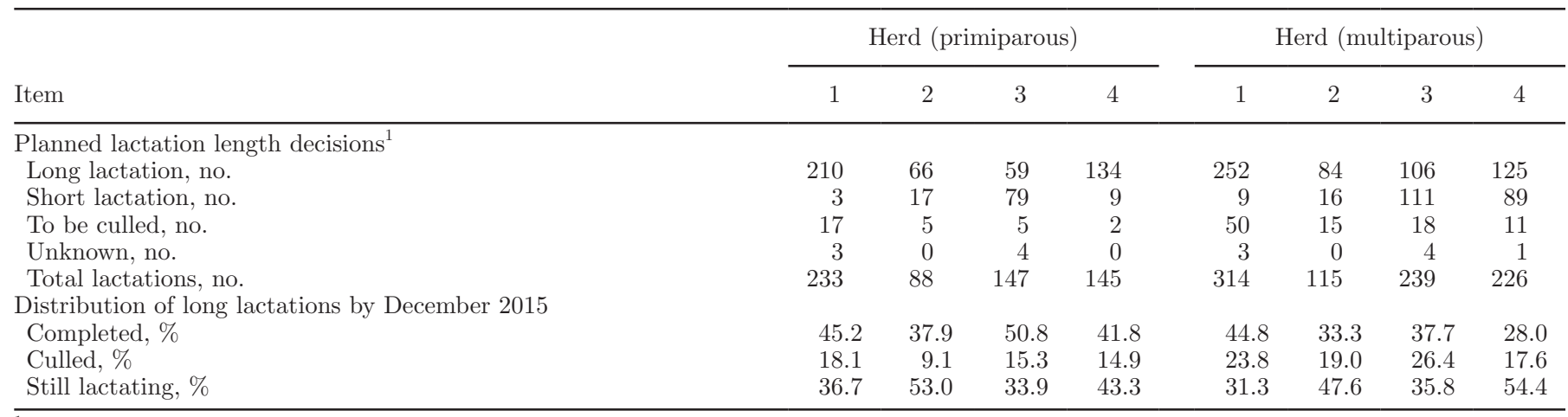

${ }^{1}$ Farmers made the decision themselves, and each farm has their own definition of how long short and long lactations are.

\section{Cows Selected for Extended Lactation}

The 4 farmers were asked every month to record which of the newly calved cows were selected for short and long lactations, respectively, as well as record which of these cows were planned to be culled. A decision was recorded for every lactation, and this amounted to a total of 1,507 lactations in the project period, of which $69 \%$ were selected for a long lactation (Table 2). In total, 422 out of 1,036 long lactations (41\%) were completed with a new calving by December 2015. The average DIM at first insemination was $53 \mathrm{~d}$ higher for cows selected for a long compared with a short lactation.

Farmers were also asked to identify risk factors for a reduced performance of cows on a long lactation by selecting and prioritizing 3 to 6 out of 22 possible riskfactors as answers to a question (translated from Danish): "What do you think could cause this cow not to perform satisfactorily during a long lactation?" These risk factors were associated with knowledge from both previous and current lactation. The farmers in herds 1,3 , and 4 recorded "a quick yield drop" in current lactation as the primary risk factor for between 73 and $97 \%$ of lactations, whereas the farmer in herd 2 viewed "low yield" to be a greater primary risk factor in current lactation. For multiparous cows, "a quick yield drop," "low yield," and "BCS in latter part of the previous lactation" were viewed as primary risk factors for 0 to $5.8 \%$ of current lactations across herds and parity groups. This indicate that farmers placed more emphasis on current rather than previous lactation information. Main secondary risk factors were "hoof and leg disorders," "mastitis," "low yield level," and "a quick yield drop" in all herds as well as the "size of the cow" in herd 3 and "milking frequency" in herds 2 and 4 where cows were milked by robots. These responses from farmers inspired our selection of variables to be included in the analyses.

\section{Data}

Dates of birth, calving, culling, drying off, insemination, pregnancy test, and disease treatments as well as recording date, milk production, fat, and protein content at monthly milk recordings were obtained from the Danish Cattle Database for cows calving between January 2013 and December 2015. Furthermore, each farm was visited every month by the same trained technician starting March 2013 where all lactating cows between 1.5 and 2.5 mo after calving as well as dry cows were scored for 5 welfare measures based on Thomsen (2005).

These welfare measures were BCS scored on a scale from 1 (very lean) to 5 (very fat) with increments of 0.25 based on Ferguson et al. (1994), lameness scored on a scale from 1 (normal walk) to 5 (severely lame) with increments of 1 based on Sprecher et al. (1997), live weight visually assessed on a scale with $50-\mathrm{kg}$ increments, hock lesions assessed on a scale from 0 (normal) to 3 (large swelling with hyperkeratosis) with increments of 1 , and hair coat condition assessed on a scale from 0 (normal) to 2 (very dull with clear indication of lack of cleaning) with increments of 1 .

\section{Variables Included in the Study}

Early lactation information was defined as the data available for each cow at 90 DIM, and thus includes a part of the current lactation and either the preceding lactation or the heifer period. Setting a cut-off at 90 DIM would allow the farmer to have a minimum of 3 monthly milk recordings available, and it would allow 2 inseminations while achieving a calving interval of approximately $13 \mathrm{mo}$, which is the current Danish average 
(Seges, 2015), should the farmer choose to inseminate the cow at 90 DIM.

In total, 14 variables were used to describe information from the previous parity, 17 were from the current parity, and the variables were continuous, count, binary, or ordinal. Information from the previous parity included age at first calving, peak milk yield, DIM at peak milk yield, 305-d lactation yield, milk yield at dry off, persistency defined as the reduction in milk yield between 60 and 305 DIM, milk yield per feeding day, dry period length, calving interval, pregnant at first insemination, days from first insemination to conception for cows not conceiving at first insemination, inseminations per conception, average dry period BCS, and average dry period lameness score.

Information from the current parity included milk yield and SCC at second ( $57 \pm 16$ DIM) and third milk recording (90 \pm 19 DIM) as well as calving process. Farmers rated the calving process on an ordinal scale with 4 levels (easy, easy with help, problematic with help, and problematic with veterinary assistance) where the 2 levels describing a problematic calving were contracted into 1 (hard). Other variables were calving with a twin, calving with minimum 1 stillborn, treated for a reproduction disease (abortions, cysts, and metritis), treated for a hoof and leg disease (any disease related to hoofs and legs), treated for a metabolic disease (grass tetany, ketosis, and calving fever), treated for an udder disease (any mastitis and injuries to teats), treated for any type of disease, BCS, lameness, live weight, hock lesions, and skin score.

Furthermore, BCS levels (range 1.75 to 4.50 with median of 3.25) lower than 2.75 were contracted to 2.75 , BCS levels greater than 3.75 were contracted to 3.75 , lameness levels 4 and 5 (4.8\% of observations) were contracted into 4, live weights were determined low, medium, or high depending the $1 / 3$ and $2 / 3$ quantile live weights within parity group within herd, hock lesion scores 2 and 3 ( $5.8 \%$ of observations) were contracted into 2 , and skin score 1 and 2 (10.7\% of observations) were contracted into 1 . This resulted in a total of 31 different variables covering the areas of milk production, fertility, disease, and welfare.

Finally, the overall performance of cows during a completed lactation was described by 6 milk production variables, dry period, and calving interval lengths, as well as 3 fertility variables and BCS at dry off. The 6 milk production variables were peak yield, DIM at peak yield, 305-d lactation yield, yield at dry off, persistency defined as per cent reduction in milk yield between 60 and 305 DIM as well as ECM per feeding day, whereas the fertility variables were pregnant at first insemination, days from first insemination to conception for cows not conceiving at first insemination, and inseminations per pregnancy.

\section{Calculations and Statistics}

Milk Performance Grouping. All completed long lactations were assigned to 1 of 3 equally sized as milk performance groups (MPG) within herd depending on ECM per feeding day (low, medium, or high) estimated as if all lactations had a calving interval of 15 mo and a dry period of $49 \mathrm{~d}$. Grouping was done separately for first, second, and third as well as fourth and greater parities within each herd, and all lactations from second and greater parities were afterward pooled to 1 . This resulted in 2 age groups (primiparous and multiparous) and 3 MPG (low, medium, and high).

A standard calving interval length of 15 mo (456 d) and a standard dry period of $49 \mathrm{~d}$ were initially assumed for all lactations to estimate a standard ECM per feeding day where potential misleading age and lactation length effects on the grouping of lactations would be avoided. The individually estimated parameters from model [1] (see later) were used to calculate the standard cumulated lactation yield of each lactation, which also gave ECM per feeding day.

Statistical Analysis. Four parts made up the statistical analysis carried out for this analysis. The first was fitting of lactation curves to previous and current lactation milk recordings to estimate a range of milk production variables and to group lactations in relation to the average milk production per feeding day within parity groups 1 through 4 within herd (MPG: low, medium, and high). The second part analyzed the production of cows during completed long lactations in relation to their MPG, and the third part analyzed the available information in early lactation determined at 90 DIM in relation to MPG. Finally, the fourth part analyzed the importance of all the variables included in the third part by carrying out a dimension reduction with a principal component analysis (PCA) followed by a varimax rotation. The varimax rotation simplifies interpretation by associating each principal component (PC) with a small number of variables through the use of correlation ratios for categorical variables and through the use of squared correlations for numerical variables (Chavent et al., 2014a).

All the statistical analyses were done with the $\mathrm{R}$ program ( $\mathrm{R}$ Development Core Team, 2015) using $\mathrm{R}$ Studio (R Studio, Boston, MA). Nonlinear fitting of lactation curves were done with the nlme-function from nlme-package in R (Pinheiro et al., 2015), and generalized linear models (GLM) of continuous, binary and count data were done with the built-in glm-function. 
Ordinal data were analyzed with the cumulative link models (CLM) function from the ordinal-package in $\mathrm{R}$ (Christensen, 2015a,b), and least squares means and contrasts were calculated with the lsmeans-package in R (Lenth, 2015) using the Tukey method. Finally, the PCA was carried out using the PCAmixdata-package in R (Chavent et al., 2014a,b). Differences were considered significant if $P<0.05$.

All model fits with a continuous outcome were evaluated with root mean squared prediction error according to Bibby and Toutenburg (1977), and all model fits with a continuous or a binary outcome were evaluated with a pseudo- $\mathrm{R}^{2}$ calculated as

$$
\left[1-\frac{\text { deviance (final model })}{\text { deviance }(\text { null model })}\right] \text {, }
$$

which is a measure of the proportion of variation in data that has been accounted for by using the final model instead of using the null model (variable mean). Likewise, fits of CLM were evaluated with a pseudo- $\mathrm{R}^{2}$ calculated in similar manner where the deviance was replaced with the log-likelihood as described by McFadden (1974). Model reduction was carried out with ANOVA using either the residual deviance or Akaike's information criterion.

Fitting Lactation Curves. Lactation curves were fitted using monthly ECM recordings (Sjaunja et al., 1991) from 422 completed long lactations as well as from 147 completed lactations preceding the 422 . This resulted in 569 lactation curves for 353 cows based on a total of 6,890 milk recordings where 69 cows had 2 consecutive completed long lactations in the data set. Of the 69 cows, 42 cows had their first and second lactation extended in the data set. Curves were fitted based on the lactation curve equation of Wilmink (1987) where 2 extra components were added. The first component was DIM squared because a standard Wilmink converges to a linear line as DIM increases, which may not hold for cows on extended lactation. The second component was a so-called Strandberg-correction (Strandberg and Lundberg, 1991), which adds a linear effect of pregnancy on milk yield based on days open. The final lactation curve model was therefore

$$
y=a+b \times e^{(-0.05 \times t)}+d \times t+e \times t^{2}+c 1 \times x \times S+\varepsilon,[1]
$$

where $y$ is ECM yield; $a, b$, and $d$ are parameters from the equation of Wilmink (1987); $t$ is time in DIM; $e$ is the coefficient for squared DIM; $c 1$ is the effect of pregnancy on ECM yield; $x$ is $t-\left(D+c_{0}\right)$, where $t$ is DIM, $D$ is days open, and $c_{0}$ is the number of days after conception when pregnancy starts to affect ECM yield; $S$ is a spline function where $S=0$ when $x<-1, S=1$ when $x>1$, and $S=(x+1)^{2} / 4$ when $-1 \leq x \leq 1$; and $\varepsilon$ is the residual. The Strandberg-correction (Strandberg and Lundberg, 1991) consists of $c 1 \times x \times S$.

Furthermore, the random intercept of the final fit was specified as lactation nested within parity group (primi- and multiparous, respectively) nested within herd (4 levels). Also, parameters $a, b, d$, and $e$ were included as random slope effects, which effectively meant that a value for these parameters were estimated for each lactation. The effect of pregnancy $(c 1)$ was assumed constant across all lactations, and $c_{0}$ was assumed equal to $160 \mathrm{~d}$ as estimated by Strandberg and Lundberg (1991).

\section{Models Used for Analyses of MPG}

Three separate groups of analyses were carried out using the following 4 models ([2]-[5]). All variables except for those related to welfare scores and the calving process were analyzed with a model that accounted for an overall herd effect (models [2] and [3]). Welfare scores and the calving process were assumed to be independent of a herd effect (models [4] and [5]) because they were all recorded according to a predefined ordinal scale by either a trained technician (welfare scores) or the farmer (calving process). Models [3] and [5] were used for variables where information only was available for multiparous cows. The 4 final models were

$$
\begin{gathered}
y_{i j k m}=\beta_{0}+\operatorname{Herd}_{i}+\mathrm{PAR}_{j}+\mathrm{MPG}_{k}+\mathrm{PAR}_{j} \times \mathrm{MPG}_{k} \\
+\varepsilon_{i j k m}, \\
y_{i k m}=\beta_{0}+\operatorname{Herd}_{i}+\mathrm{MPG}_{k}+\varepsilon_{i k m}, \\
y_{j k m}=\beta_{0}+\mathrm{PAR}_{j}+\mathrm{MPG}_{k}+\mathrm{PAR}_{j} \times \mathrm{MPG}_{k}+\varepsilon_{j k m},[4] \\
y_{k m}=\beta_{0}+\mathrm{MPG}_{k}+\varepsilon_{k m},
\end{gathered}
$$

where $y_{i j k m}, y_{i k m}, y_{j k m}$, and $y_{k m}$ were the response variables of models [2] through [5], respectively; $\beta_{0}$ was the common intercept; Herd $_{i}$ was the factorial effect of herd $i$ (4 levels); $\mathrm{PAR}_{j}$ was the factorial effect of parity group $j$ (primi- and multiparous); $\mathrm{MPG}_{k}$ was the factorial effect of milk performance group $k$ (low, medium, and high), and $\mathrm{PAR}_{j} \times \mathrm{MPG}_{k}$ was the interaction effect between parity group $j$ and milk performance group $k$. The $\varepsilon_{i j k m}, \varepsilon_{i k m}, \varepsilon_{j k m}$, and $\varepsilon_{k m}$ were the residual effects of models [2] through [5], respectively. 


\section{Performance During a Completed Lactation}

All milk production variables were estimated based on individual lactation curves (model [1]) as well as individual lactation and dry period lengths. All variables were analyzed in relation to parity group (primi- and multiparous) and MPG (low, medium, and high) where model [2] was used to analyze all variables except for BCS at dry off, which was analyzed with model [4]. For these analyses, model [2] was specified as a GLM, whereas model [4] was specified as a CLM.

\section{Early Lactation Information}

All variables where information was available for both primi- and multiparous cows were analyzed in relation to parity group (primi- and multiparous) and MPG (low, medium, and high) with model [2] except for welfare variables and the calving process as they were analyzed with model [4]. All variables that were only available for multiparous cows were analyzed with model [3] except for welfare scores as they were analyzed with model [5]. For the analyses, models [2] and [3] were specified as GLM, whereas models [4] and [5] were specified as CLM.

\section{Clustering of Available Information}

The PCA was carried out separately for primi- and multiparous cows because the available information differed, and because the importance of the variables could depend on parity group. The PCA method of Chavent et al. (2014a) is capable of handling a mixed data set with both continuous and ordinal variables, and it handles missing values by replacing those in continuous variables with the mean and those in ordinal variables with zeros. Orthogonal rotation was carried out by maximizing the varimax-function (Chavent et al., 2014b).

The resulting squared loadings are squared correlations and correlation ratios between the variable and the $\mathrm{PC}$ for continuous and ordinal variables, respectively. A PC was kept if it accounted for a minimum of $5 \%$ of the total variance in the data set. Variables were said to affect a PC if the squared loading of this variable in this $\mathrm{PC}$ was 0.5 or greater, and variables were kept if minimum $15 \%$ of its sum of squared loadings was accounted for by the retained PC.

\section{RESULTS}

\section{Performance During a Completed Lactation}

The grouping of completed long lactations according to a standardized 15-mo calving interval and 49-d dry period was reflected in a significantly increased kilograms of ECM per feeding day from low to high MPG for both primi- and multiparous cows (Table 3). Milk performance group was significantly related to all tested variables except for DIM at peak yield and dry period length, whereas parity group did not significantly relate to milk yield at dry off, calving interval, or any of the fertility variables. The interaction between parity group and MPG was only significant for 305-d lactation yield and ECM per feeding day, which means that the difference between MPG was greatest for multiparous cows. The variables dry period length, percent pregnant at first insemination, and dry period BCS had the lowest proportion of variance explained by the model.

Both primi- and multiparous cows in high MPG were characterized by having a significantly greater peak yield, lower percent reduction in milk yield between 60 and 305 DIM, and a longer calving interval when compared with the respective low MPG of primi- and multiparous cows. Furthermore, the percentage of cows conceiving at first insemination was lower in high MPG, and those cows that did not conceive at first insemination took a longer time to conceive afterward when compared with low MPG, and this was also reflected in a higher number of inseminations per conception. However, all 3 fertility variables had relatively low $R^{2}$ (0.06-0.22).

Dry period BCS was significantly related to both parity group and MPG, but a model with these 2 factors only resulted in a $R^{2}$ of 0.01 . Nevertheless, a lower percentage of cows in high MPG had a BCS of 3.50 or greater, and a greater percentage of them had a BCS of 3.00 or lower when compared with cows in low MPG.

\section{Early Lactation Information}

The type of information available in early lactation (by 90 DIM) differed across parity groups as only age at first calving and fertility variables from the heifer period were available for primiparous cows (Table 4). Primiparous cows in high MPG were 1.8 mo older at first calving and needed an average 0.3 inseminations more per conception when compared with low MPG, although the $\mathrm{R}^{2}$ of age at first calving and inseminations per conception only were 0.13 and 0.07 , respectively. In comparison, age at first calving was not different across MPG for multiparous cows, whereas the same effect was seen for inseminations per conception. Although not statistically significant, we did find that previous lactation conception to first insemination was 11 percentage units lower for both primi- and multiparous cows in high MPG compared with low MPG.

All milk production variables from the previous lactation except for peak yield were significantly different 


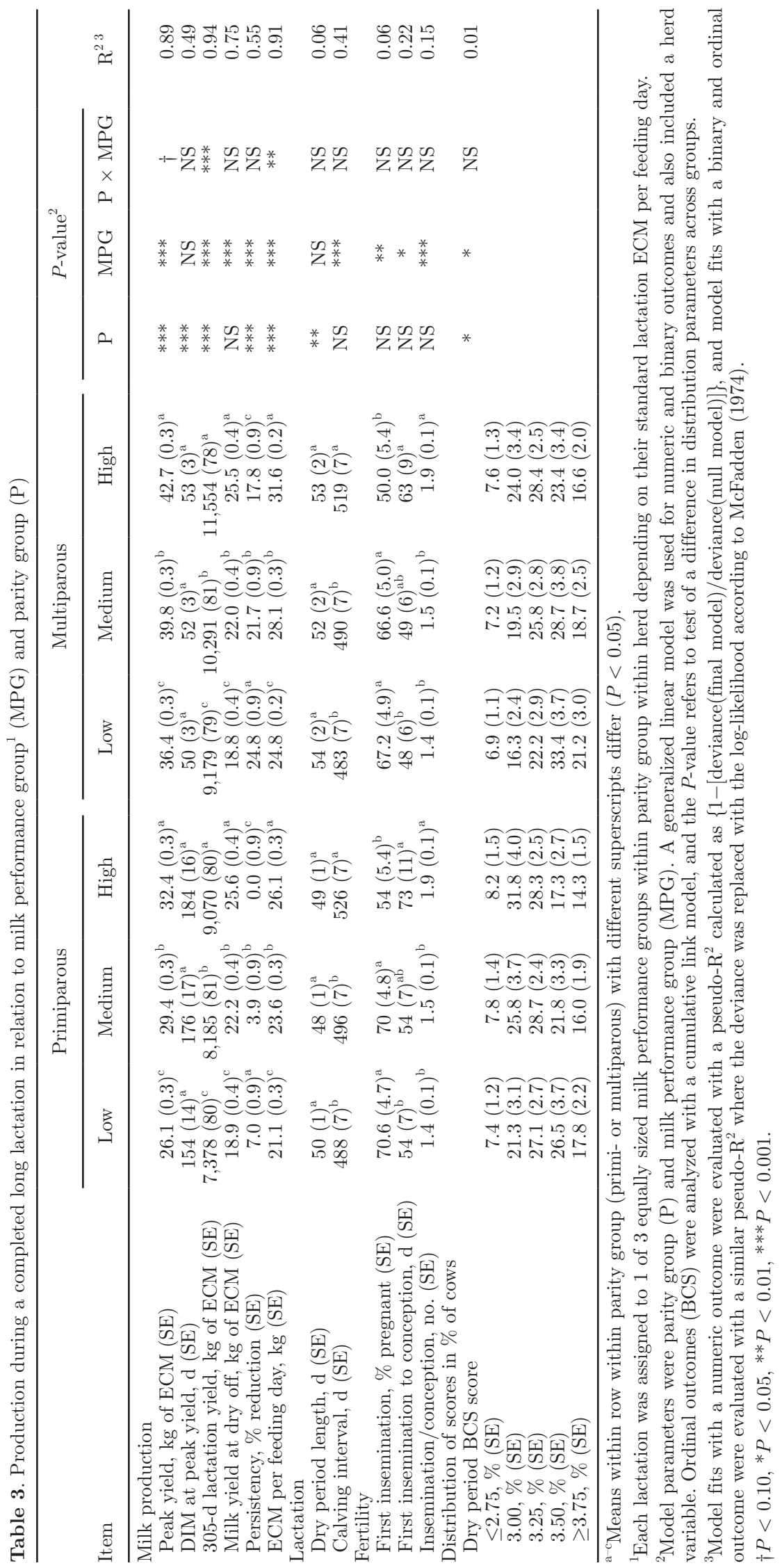


across MPG for multiparous cows, and $\mathrm{R}^{2}$ ranged from 0.06 (persistency) to 0.73 (milk yield at dry off). Multiparous cows in high MPG peaked later, produced more milk the first $305 \mathrm{~d}$ of lactation, had a higher yield at dry off, and had a smaller per cent milk yield reduction between 60 and 305 DIM as well as a 6-d longer dry period during the previous lactation when compared with the multiparous cows in low MPG. No difference was found in the distribution of BCS or lameness scores across MPG for multiparous cows, but the proportion of lame cows was numerically lower, and the percentage of cows with a BCS of 3.50 or greater was numerically higher for cows in high MPG compared with low MPG.

For information from the early part of the current lactation, $\mathrm{R}^{2}$ was low, ranging from 0.01 to 0.11 for all variables except the 2 variables describing milk production where $\mathrm{R}^{2}$ was 0.83 and 0.86 for yield at second and third recording, respectively (Table 5). Milk production was consistently and substantially greater (21-24\%) at second and third milk recording for cows in high MPG compared with low MPG across parity groups.

Cows in low MPG tended $(P<0.1)$ to have a greater proportion of assisted calvings, and numerically, a greater percentage of calvings from the low MPG resulted in a minimum of 1 dead calf. The proportion of cows treated by a veterinarian were not different across MPG, and the percentage of cows treated for reproduction, metabolic, or hoof- and leg-related diseases were virtually zero across MPG and parity groups (data not shown). Numerically, the percentage of treated cows was greatest in the low MPG.

Body condition score was significantly different and lameness score as well as live weight group tended to be different across MPG in current early lactation, whereas neither hock lesions nor skin score were different. The percent of lean cows with a BCS of 2.75 or less was greatest for cows in low and high MPG compared with medium MPG, which had the greatest percent of cows with a BCS of 3.00 or greater. In contrast, a greater percentage of cows in the high MPG were consistently in the high live weight group, whereas a greater percentage of the cows in the low MPG were found to have hock lesions. Also, the percentage with a skin score of 1 or 2 was consistently greater in the low MPG across parity groups in current early lactation when compared with high MPG.

\section{Clustering of Available Information}

The results of the PCA (Table 6) indicated that 5 and $3 \mathrm{PC}$ added minimum $5 \%$ to the cumulated proportion of variance explained for primi- and multiparous cows, respectively, and this resulted in a cumulated proportion of variance explained of 37.9 and $25.9 \%$, respec- tively. The PCA included all variables listed in Tables 4 and 5 where 15 out of the 31 variables had a substantial effect on the retained PC as minimum $15 \%$ of their cumulated rotated squared loadings were included for either primi- or multiparous cows. Variables with less than $15 \%$ were age at first calving, dry period length, dry period BCS and lameness, SCC at second and third milk recording, calving with a twin and minimum of 1 dead calf, treated for reproduction, metabolic, and udder diseases as well as all early lactation welfare recordings. Besides calving process and 2 disease treatment variables, previous lactation persistency had the lowest proportion of squared loadings included by the retained PC (19.3\%), whereas previous ECM per feeding day had the greatest proportion included across parity groups.

The varimax-rotation led to a clear separation of total variance into uncorrelated $\mathrm{PC}$, and variables with a squared loading of 0.5 or greater was used to classify a PC. For primiparous cows, the first, second, and third PC were clearly described by variables related to fertility, disease treatments, and milk yield, respectively, whereas both the fourth and fifth PC were affected primarily by the calving process. Primiparous PC 1 was, therefore, predominantly affected by "pregnant at first insemination," "days from first insemination to conception," and "inseminations per conception"; PC 2 was predominantly affected by treatments for diseases related to hoofs and legs and the variable containing all treatments; and PC 3 was predominantly affected by milk yield at second and third milk recording.

Multiparous PC 1 was affected by 6 milk yield variables, PC 2 by fertility, and PC 3 by DIM at peak milk yield and to a smaller extent by persistency, although the squared loading only was 0.17 . Multiparous PC 1 was affected by peak yield, 305-d lactation yield, milk yield at dry off, ECM per feeding day and milk yield at second and third milk recording. Except for PC 1, primiparous cows were predominantly affected by variables related to current lactation; whereas, multiparous cows predominantly were affected by variables related to the previous lactation.

\section{DISCUSSION}

The nature of our analysis is not that of a designed, randomized, and controlled experiment, but rather more of a descriptive study based on nonexperimental farm data. As such, this precludes hypothesis testing of causal relationships; however, it does allow us to investigate and discuss structures in data. A biological and technical interpretation of these structures, therefore, must precede any causal inference to the remaining Danish cattle population. Furthermore, only 4 farms 


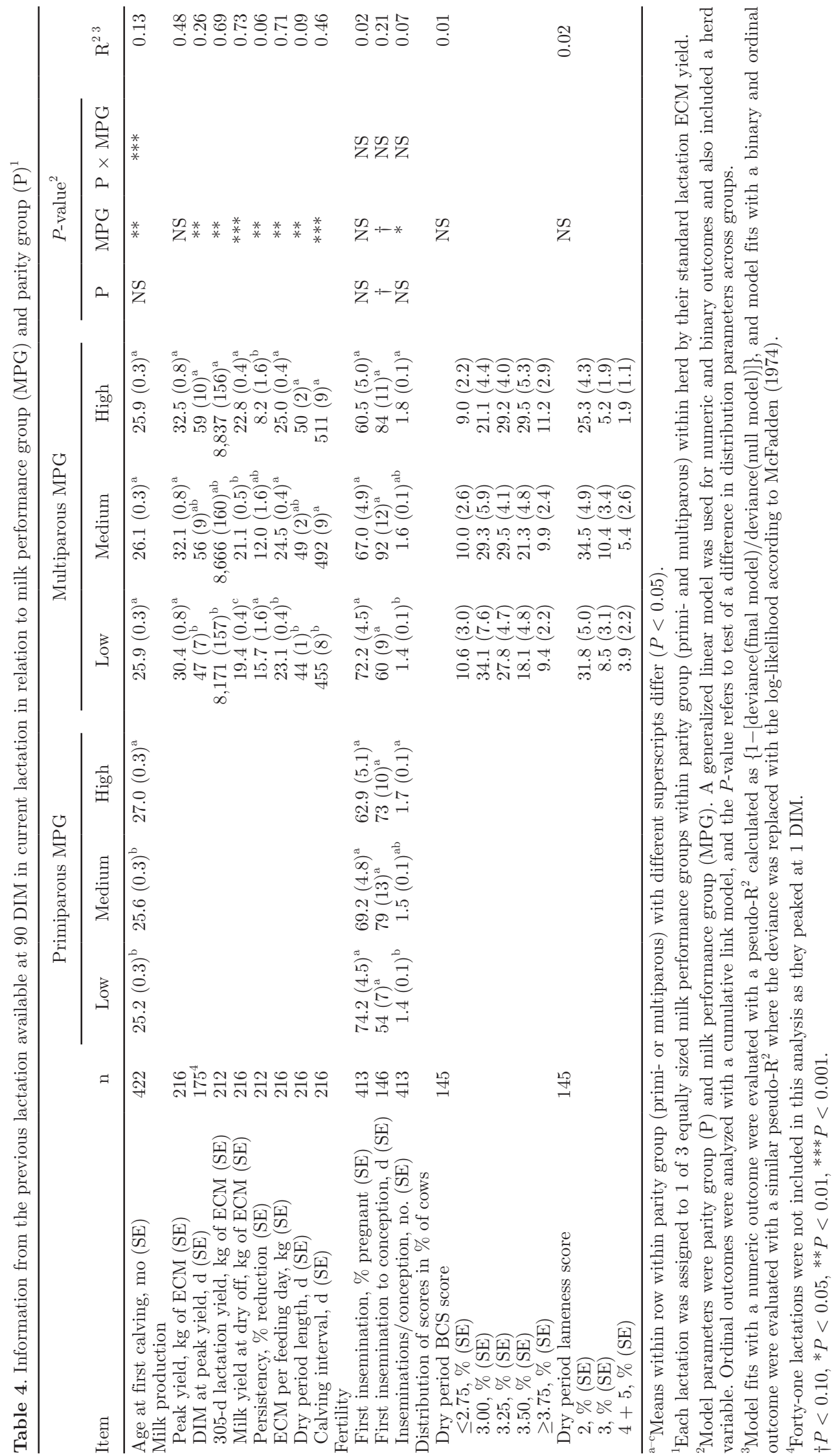




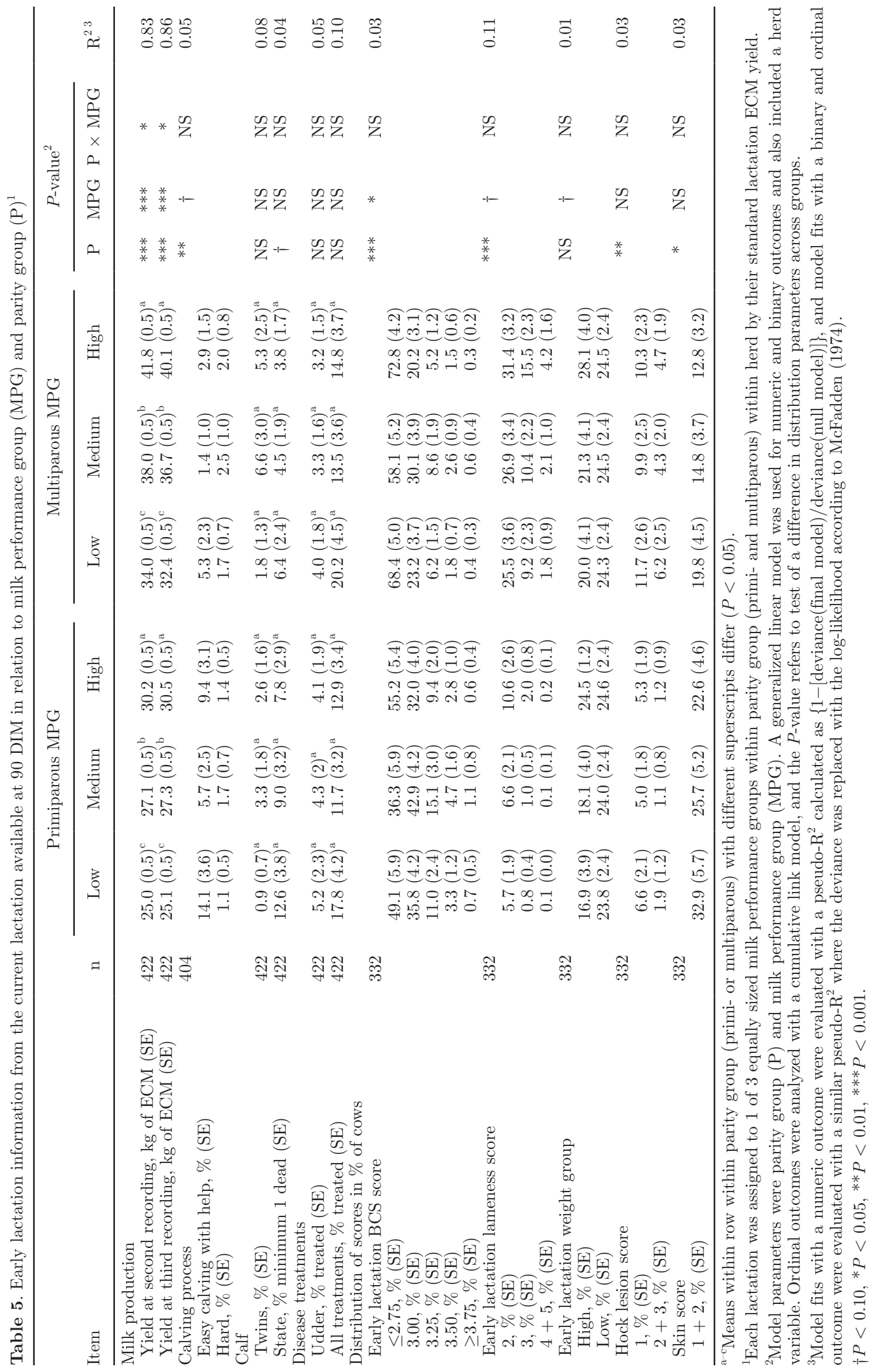


EXTENDED LACTATION AND MILK PERFORMANCE

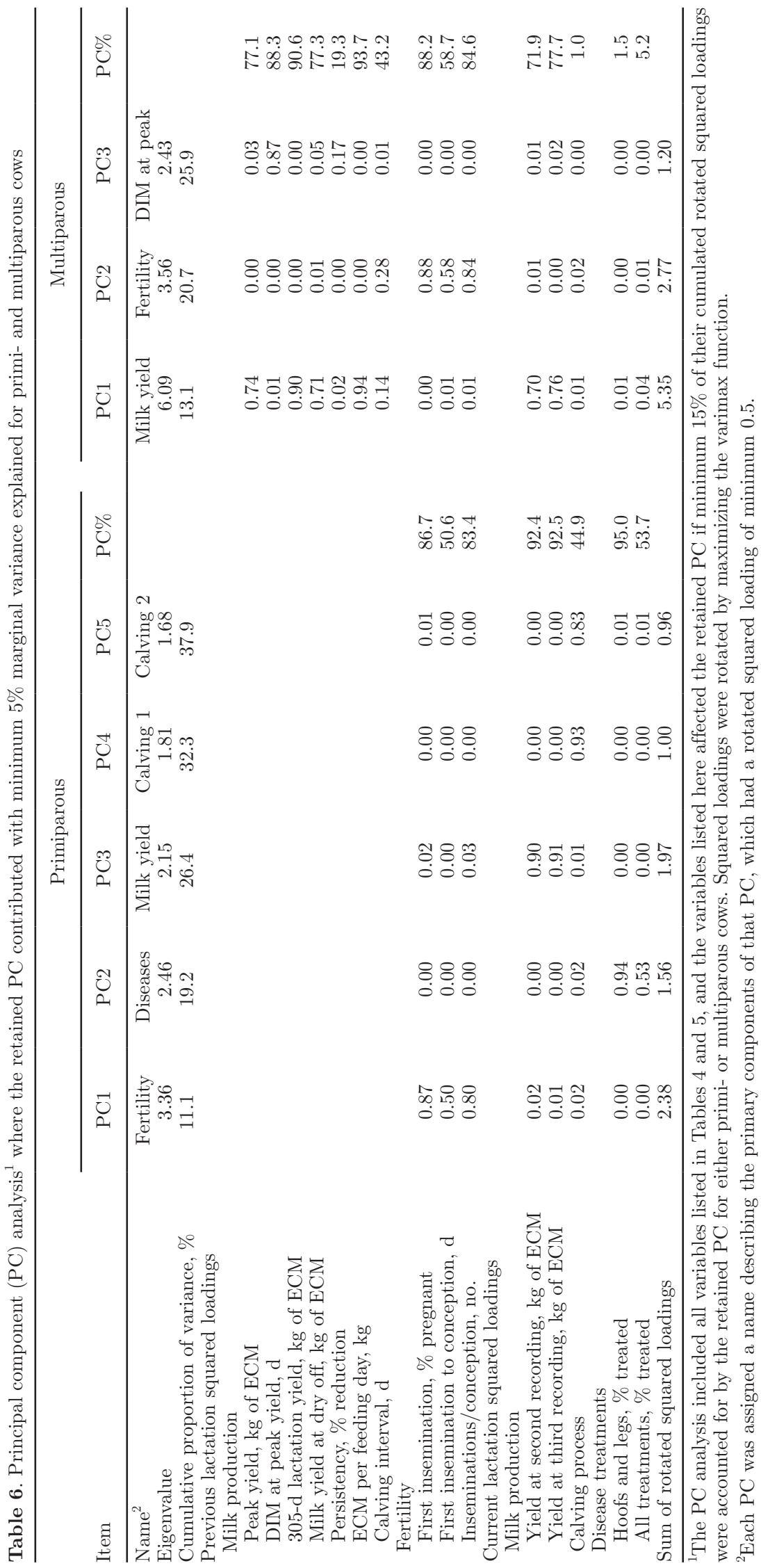


were included in our study, and a larger number of herds would have allowed the general management perspective to be included in the analysis and thereby have increased the ability to explain differences across groups of cows.

The herds included in our study are representative of Danish dairy herds, which averaged 165 annual cows, $10,823 \mathrm{~kg}$ of ECM per annual cow, and a replacement rate of 39.4\% for Holstein herds in 2015 (Lauritsen and Flagsted, 2015). In comparison, Jersey herds averaged 187 annual cows, 9,673 $\mathrm{kg}$ of ECM per annual cow and had a replacement rate of $34.9 \%$. However, we only used the completed extended lactations for this investigation where the farmer selected cows in early lactation to have insemination delayed. In contrast, cows undergoing extended lactation in many other studies (e.g., Vargas et al., 2000; Dematawewa et al., 2007; Pollott, 2011) likely did so as a result of failed conception. Yet, we also saw that calving interval length increased with increasing MPG, which was accompanied by a reduction in percent pregnant at first insemination, an increased time from first insemination to conception, and an increased number of inseminations per conception. This may illustrate that high-producing cows have a greater chance to remain in the herd even if this results in a longer calving interval and lower conception rates because the farmer is willing to accept this in return for an expected higher production.

Our results, therefore, presume that the cow successfully completes the extended lactation with a new calving, but it should also be noted that less than half of the initiated lactations were completed by the end of the project period. This is a standard issue when using data from farms where cows calve continuously throughout the year as cows thereby continuously enter and leave the lactating group. Therefore, $40 \%$ of initiated extended lactations were still lactating at the end of the project period.

Our study indicated that there generally seems to be a high degree of repeatability among milk yield variables as cows in high MPG had high milk yields in the previous lactation, early current lactation, and during the completed current lactation. To our knowledge, only one other study has been published that has looked at indicators for selection of cows for extended lactation (Kay et al., 2007). These authors correlated several markers of production, genetics, and physiology with milk production during the extended part of a 2-yr pasture-based lactation in New Zealand, and also found that previous lactation milk yield may be a good indicator of current lactation milk production, although they in many cases found as low $\mathrm{R}^{2}$ (majority was $\leq 0.19)$ as we did. Kay et al. (2007) suggested that especially thinner, high-producing cows were suitable for extended lactation, and based this on their observation that early lactation plasma insulin and BCS at the beginning of the extended part of the lactation correlated well with final milk solids production.

This repeatability in milk yield is also in line with the relatively high genetic correlation generally found between first and second lactation milk yield (Dong and Van Vleck, 1989; Strabel and Misztal, 1999), which substantiates the notion of repeatability in milk yield across lactations. Also, milk yield at first recording has been positively correlated with total yield during the first $100 \mathrm{~d}$ of lactation and was found to be a better predictor than BCS at calving according to Heuer et al. (1999). Their average DIM at their first milk recording was 18 , and we argue that using the first monthly milk recording may not be optimal as it may coincide with a high acceleration of the lactation curve and be from a few days after calving.

Other studies have looked into the effect of early lactation yield on conception (e.g., Madouasse et al., 2010) and of early lactation SCC on milk production (e.g., De Vliegher et al., 2005), but reproduction and disease as well as welfare and production are 4 key aspects of dairy farming that appear to be related in a complicated interaction pattern (Fourichon et al., 1999; Roche et al., 2009; Bello et al., 2012). These 3 reviews illustrate the difficulty in using 1 or more variables related to reproduction, disease, and welfare to estimate the future production of a dairy cow, and they illustrate the difficulty in assessing relationships such as if high yield causes low reproduction or vice versa, and if high yield causes poor welfare or vice versa. Also, we saw that both low and high MPG had a higher proportion of lean cows in early lactation compared with medium MPG, and it raises the question if cows become lean because they mobilize reserves for milk production, or because they are affected by disease. Our data suggest that these 2 situations may very well occur simultaneously in a herd.

Combining an analysis of the association between early lactation information and MPG with a PCA of these early lactation variables allows for pointing toward a reduced number of indicators, which could be used to select cows with high milk production potential as the PCA reduces complexity by joining correlated variables.

We used the PCA to detect variables that explained a high proportion of the total variation in the data set, and these variables were then tested for their association with MPG. We thereby tested them for their ability to be used as selection indicators. Some of these tests resulted in low $\mathrm{R}^{2}$, and despite numerically high differences, these differences were not always significant, which likely is due to management decisions and low 
biological relations (e.g., previous conception to first insemination and current MPG). These implications are important to keep in mind when searching for relevant indicators. The 2 following sections discuss potential indicators separately for primi- and multiparous cows.

\section{Potential Indicators: Primiparous Cows}

Fertility variables (91\% of squared loadings) from the heifer period clearly affected the first PC found for primiparous cows (11.1\% of variance), but the link between each fertility variable and MPG was not clear as $R^{2}$ was low, and only the variable "inseminations per conception" came out as being related to MPG. In contrast, all 3 fertility variables for completed primiparous lactations were different across MPG, and they generally indicated that fertility was negatively associated with MPG, and heifer fertility showed the same trend. From a management perspective, this is counterintuitive, as aiming for highest milk yield would imply aiming for low fertility. Also, this may be a question of whether low fertility caused high milk yield or high milk yield caused low fertility (Bello et al., 2012), but a low fertility is not a guarantee of a high milk production.

The 2 disease variables related to "hoof and legs" and "all treatments" (94\% of squared loadings) affected the second PC ( $8.1 \%$ of variance), and here the link to MPG was also not very clear with $\mathrm{R}^{2}$ being less than 0.1 , and no significance was detected. Only the variables encompassing all treatments were both retained by the PCA and indicated a numeric but nonsignificant difference where fewer cows in the high MPG were treated compared with low MPG. Early lactation milk yield (92\% of squared loadings) clearly affected the third PC (7.1\% of variance), and here there was a clear relation with MPG with a relatively high $\mathrm{R}^{2}(0.83$ and 0.86). In fact, cows in high MPG produced 5.1 and $5.4 \mathrm{~kg}$ of ECM more at the second and third milk recording, respectively, compared with the low MPG, and the level of production at these 2 milk recordings may, therefore, be a good indicator of milk production during a completed lactation.

The calving process dominated both fourth and fifth PC, but the link with MPG was not very strong $(P<$ 0.1 ), and $\mathrm{R}^{2}$ was low (0.05). Cows in the high MPG did have fewer assisted calvings compared with the low MPG, but the medium MPG had even fewer assisted calvings, which makes the intuitive interpretability less clear when seen in a management context. Perhaps 2 distinct situations can occur despite the same calving process, but we do not have the data to explore this.

\section{Potential Indicators: Multiparous Cows}

Milk yield variables (77\% of squared loadings) clearly affected the first multiparous PC, and the link with MPG was clear and consistent with $\mathrm{R}^{2}$ being 0.5 or greater for milk production variables from both the previous and the current lactation. This finding has an interesting management perspective as cows in high MPG had a high milk yield in both the previous lactation and at the second and third milk recording of the current lactation.

Fertility variables from the previous lactation clearly affected the second PC, and here the same trend was seen as with the first primiparous PC. A large proportion of the variance within these variables was accounted for by the retained PC, but the link with MPG was not very clear as $\mathrm{R}^{2}$ was low, and only inseminations per conception were significant. Also, cows in the high MPG had a lower chance of conceiving at first insemination and required more inseminations per conception, which again may be counterintuitive when seen in a management perspective.

Days in milk at peak yield and to a lesser extent persistency from the previous lactation affected the third $\mathrm{PC}$, and a clear relationship was found between MPG and both DIM at peak yield and persistency, but $\mathrm{R}^{2}$ was low for both variables. For multiparous completed lactations, DIM at peak yield did not differ, whereas persistency did, and cows in high MPG had a low reduction in milk yield between 60 and 305 DIM in both the previous and the current lactation. However, $\mathrm{R}^{2}$ was low for persistency from the previous lactation, and $\mathrm{R}^{2}$ was reasonable for the completed current lactation, which indicates that persistency may not correlate well across lactations.

\section{Concluding Remarks}

The results of our study may appear disappointing because so much information on the individual lactation was included. However, this may be related to an apparent ambiguity in the cause-effect relationship for some variables. For example, the highest proportion of cows with a low early lactation BCS was found for both cows in low and high MPG, and this indicates that the complexity is greater, for which reason other variables such as genetics and feed intake besides parity group and MPG have to be included as well. Furthermore, many of the variables tested with the linear model had very low degrees of variance explained, and both the primi- and multiparous PCA were characterized by a relatively low proportion of variance explained by the retained $\mathrm{PC}$. 
Our study indicated a high degree of repeatability in milk production across lactations, and that early lactation milk yield to some extent correlates well with the milk performance during an extended lactation. Further research is required to elucidate if and how information on early lactation can be combined with information of previous and current reproduction, disease and welfare to assist farmers in choosing which cows to delay insemination, and hence which cows can be managed for an extended lactation. Ultimately, this could point out what information future decision support solutions for dairy farmers could include when evaluating individual cows for extended lactation, and thus assist farmers in utilizing the milk production potential of cows for longer.

\section{ACKNOWLEDGMENTS}

This project was funded by the Danish Council for Strategic Research (Copenhagen, Denmark), and the lead author was partially funded by a scholarship from the Graduate School of Science and Technology at Aarhus University, Denmark.

\section{REFERENCES}

Albarrán-Portillo, B., and G. E. Pollott. 2011. Environmental factors affecting lactation curve parameters in the United Kingdom's commercial dairy herds. Arch. Med. Vet. 43:145-153.

Arbel, R., Y. Bigun, E. Ezra, H. Sturman, and D. Hojman. 2001. The effect of extended calving intervals in high-yielding lactating cows on milk production and profitability. J. Dairy Sci. 84:600-608.

Barrier, A. C., and M. J. Haskell. 2011. Calving difficulty in dairy cows has a longer effect on saleable milk yield than on estimated milk production. J. Dairy Sci. 94:1804-1812.

Bello, N. M., J. S. Stevenson, and R. J. Tempelman. 2012. Invited review: Milk production and reproductive performance: Modern interdisciplinary insights into an enduring axiom. J. Dairy Sci. 95:5461-5475.

Bibby, J., and H. Toutenburg. 1977. Prediction and Improved Estimation in Linear Models. Wiley, London, UK.

Chavent, M., V. Kuentz, A. Labenne, B. Liquet, and J. Saracco. 2014b. PCAmixdata: Multivariate Analysis of Mixed Data. $\mathrm{R}$ package version 2.2 [2014-12-05]. R Foundation for Statistical Computing, Vienna, Austria. http://CRAN.R-project.org/ package $=$ PCAmixdata.

Chavent, M., V. Kuentz-Simonet, A. Labenne, and J. Saracco. 2014a. Multivariate analysis of mixed data: The PCAmixdata R package. ArXiv e-prints:1411.4911.

Christensen, R. H. B. 2015a. Analysis of ordinal data with cumulative link models - Estimation with the R-package ordinal. R Foundation for Statistical Computing, Vienna, Austria. https://cran.rproject.org/web/packages/ordinal/vignettes/clm_intro.pdf.

Christensen, R. H. B. 2015b. ordinal: Regression Models for Ordinal Data. R package version 2015.6-28 [2015-06-28]. R Foundation for Statistical Computing, Vienna, Austria.

De Vliegher, S., H. W. Barkema, H. Stryhn, G. Opsomer, and A. de Kruif. 2005. Impact of early lactation somatic cell count in heifers on milk yield over the first lactation. J. Dairy Sci. 88:938-947.

Dematawewa, C. M., R. E. Pearson, and P. M. Vanraden. 2007. Modeling extended lactations of Holsteins. J. Dairy Sci. 90:3924-3936.
Dong, M. C., and L. D. Van Vleck. 1989. Correlations among first and second lactation milk yield and calving interval. J. Dairy Sci. 72:1933-1936.

Ettema, J. F., and J. E. P. Santos. 2004. Impact of age at calving on lactation, reproduction, health, and income in first-parity Holsteins on commercial farms. J. Dairy Sci. 87:2730-2742.

Ferguson, J. D., D. T. Galligan, and N. Thomsen. 1994. Principal descriptors of body condition score in Holstein cows. J. Dairy Sci. 77:2695-2703.

Fourichon, C., H. Seegers, N. Bareille, and F. Beaudeau. 1999. Effects of disease on milk production in the dairy cow: A review. Prev. Vet. Med. 41:1-35.

Funk, D. A., A. E. Freeman, and P. J. Berger. 1987. Effects of previous days open, previous days dry, and present days open on lactation yield. J. Dairy Sci. 70:2366-2373.

Green, L. E., V. J. Hedges, Y. H. Schukken, R. W. Blowey, and A J. Packington. 2002. The impact of clinical lameness on the milk yield of dairy cows. J. Dairy Sci. 85:2250-2256.

Heuer, C., Y. H. Schukken, and P. Dobbelaar. 1999. Postpartum body condition score and results from the first test day milk as predictors of disease, fertility, yield, and culling in commercial dairy herds. J. Dairy Sci. 82:295-304.

Kay, J. K., P. W. Aspin, C. V. C. Phyn, J. R. Roche, and E. S. Kolver. 2007. Production and physiological indicators to select cows suitable for extended lactations. Pages 315-319 in Proceedings of the New Zealand Society of Animal Production. Vol. 67. Hamilton, New Zealand.

Lauritsen, U., and P. Flagsted. 2015. Monthly milk recording statistic - Results from 2015/1/1 to 2015/12/31 (Original Danish title: Ydelseskontrollens månedsstatistik. Periode: 1/1/15 - 31/12/15). Accessed Mar. 4, 2016. https://www.landbrugsinfo.dk/Kvaeg/Talom-kvaeg/Sider/mndstatmain12.aspx.

Lehmann, J. O., J. G. Fadel, L. Mogensen, T. Kristensen, C. Gaillard, and E. Kebreab. 2016. Effect of calving interval and parity on milk yield per feeding day in Danish commercial dairy herds. J. Dairy Sci. 99:621-633.

Lenth, R. V.. 2015. lsmeans. R package version 2.15 [2015-02-07]. R Foundation for Statistical Computing, Vienna, Austria. http:// CRAN.R-project.org/package=lsmeans.

Madouasse, A., J. N. Huxley, W. J. Browne, A. J. Bradley, I. L. Dryden, and M. J. Green. 2010. Use of individual cow milk recording data at the start of lactation to predict the calving to conception interval. J. Dairy Sci. 93:4677-4690.

McFadden, D. 1974. Conditional Logit Analysis of Qualitative Choice Behavior. Pages 105-142 in Frontiers in Econometrics. P. Zarembka, ed. Academic Press, New York, NY.

Nielsen, H. M., N. C. Friggens, P. Løvendahl, J. Jensen, and K. L. Ingvartsen. 2003. Influence of breed, parity, and stage of lactation on lactational performance and relationship between body fatness and live weight. Livest. Prod. Sci. 79:119-133.

Onyiro, O. M., J. Offer, and S. Brotherstone. 2008. Risk factors and milk yield losses associated with lameness in Holstein-Friesian dairy cattle. Animal 2:1230-1237.

Österman, S., and J. Bertilsson. 2003. Extended calving interval in combination with milking two or three times per day: Effects on milk production and milk composition. Livest. Prod. Sci. 82:139149.

Pinheiro, J., D. Bates, S. DebRoy, D. Sarkar, EISPACK authors, and R Development Core Team. 2015. nlme: Linear and Nonlinear Mixed Effects Models. R package version 3.1-122 [2015-08-19]. R Foundation for Statistical Computing, Vienna, Austria. http:/ cran.r-project.org/web/packages/nlme/index.html.

Pollott, G. E. 2011. Do Holstein lactations of varied lengths have different characteristics? J. Dairy Sci. 94:6173-6180.

R Development Core Team. 2015. R: A language and Environment for Statistical Computing. Version 3.2.2 [2015-08-14]. R Foundation for Statistical Computing, Vienna, Austria. http://www.r-project. org.

Rajala-Schultz, P. J., Y. T. Gröhn, and C. E. McCulloch. 1999. Effects of milk fever, ketosis, and lameness on milk yield in dairy cows. J. Dairy Sci. 82:288-294. 
Roche, J. R., N. C. Friggens, J. K. Kay, M. W. Fisher, K. J. Stafford, and D. P. Berry. 2009. Invited review: Body condition score and its association with dairy cow productivity, health, and welfare. J. Dairy Sci. 92:5769-5801.

Seges. 2015. Handbook of cattle production (Original Danish title: Håndbog i Kvæghold). SEGES Forlag, Skejby, Denmark.

Sjaunja, L. O., L. Bævre, L. Junkkarinen, J. Pedersen, and J. Setälä. 1991. A Nordic proposal for an energy corrected milk (ECM) formula. Pages 156-157 in Performance Recording of Animals: State of the Art, 1990. EAAP publication 50. P. Gaillon and Y. Chabert, ed. Centre for Agricultural Publishing and Documentation (PUDOC), Wageningen, the Netherlands.

Sprecher, D. J., D. E. Hostetler, and J. B. Kaneene. 1997. A lameness scoring system that uses posture and gait to predict dairy cattle reproductive performance. Theriogenology 47:1179-1187.

Steeneveld, W., Y. H. Schukken, A. T. van Knegsel, and H. Hogeveen. 2013. Effect of different dry period lengths on milk production and somatic cell count in subsequent lactations in commercial Dutch dairy herds. J. Dairy Sci. 96:2988-3001.
Strabel, T., and I. Misztal. 1999. Genetic parameters for first and second lactation milk yields of Polish black and white cattle with random regression test-day models. J. Dairy Sci. 82:2805-2810.

Strandberg, E., and C. Lundberg. 1991. A note on the estimation of environmental-effects on lactation curves. Anim. Prod. 53:399-402.

Thompson, J. R., E. J. Pollak, and C. L. Pelissier. 1983. Interrelationships of parturition problems, production of subsequent lactation, reproduction, and age at first calving. J. Dairy Sci. 66:1119-1127.

Thomsen, P. T. 2005. Loser cows in Danish dairy herds with loosehousing systems: Definition, prevalence, consequences and risk factors. PhD Thesis. The Royal Veterinary and Agricultural University, Copenhagen, Denmark.

Vargas, B., W. J. Koops, M. Herrero, and J. A. M. van Arendonk. 2000. Modeling extended lactations of dairy cows. J. Dairy Sci. 83:1371-1380.

Wilmink, J. B. M. 1987. Adjustment of test-day milk, fat and protein yield for age, season and stage of lactation. Livest. Prod. Sci 16:335-348. 